\title{
VINTE E CINCO ANOS DE REAÇÕES, ESTRATÉGIAS E METODOLOGIAS EM QUÍMICA ORGÂNICA
}

\author{
Carlos Roque D. Correia \\ Instituto de Química, Universidade Estadual de Campinas, CP 6154, 13081-970 Campinas - SP
}

Paulo R. R. Costa

Núcleo de Pesquisa de Produtos Naturais, Universidade Federal do Rio de Janeiro, CCS, Bloco H, 21941-590 Rio de Janeiro - RJ

Vitor F. Ferreira*

Departamento de Química Orgânica, Instituto de Química, Universidade Federal Fluminense, Outeiro de São João Batista, s/n, 24020-150 Niterói - RJ

\begin{abstract}
TWENTY FIVE YEARS OF STRATEGIES, METHODOLOGIES AND REACTIONS IN ORGANIC CHEMISTRY. An overview of the developments that occurred in the field of organic chemistry in Brazil in the last 25 years is presented. These developments are briefly compared to those observed worldwide, including some modern trends. The main source of information was the annual meeting of the Brazilian Chemical Society (RASBQ) covering the period 1979-2001 and the biennial Brazilian Meeting on Organic Synthesis (BMOS). All the contributions presented at these two meetings were classified according to six main indicatives, to permit a discussion about the past, present and future activities of Organic Chemistry in Brazil.
\end{abstract}

Keywords: SBQ; Brazilian Chemical Society; organic chemistry overview.

\section{INTRODUÇÃO}

\begin{abstract}
"A SBQ tem por finalidade congregar químicos ou outras pessoas que trabalham e tenham interesse em química, com a finalidade de desenvolver, divulgar e promover o desenvolvimento da pesquisa, da educação e das aplicações práticas da química, zelando pelo alto nível científico da química no País" (art.2 do Estatuto da SBQ).
\end{abstract}

Comemora-se, neste ano, os vinte e cinco anos de existência da Sociedade Brasileira de Química (SBQ). A história da Química Orgânica confunde-se, neste período, com a história da própria SBQ, que uniu em suas reuniões anuais e congressos uma parte expressiva dos pesquisadores e estudantes de nossas instituições de ensino superior dedicados a esta disciplina.

Está fora do escopo deste artigo fazer um histórico da criação da Química Orgânica no Brasil, porém cabe lembrar, especialmente como registro de memória para os leitores jovens, que ao redor dos anos 60 dois importantes grupos de pesquisa foram criados no país, um no Rio de Janeiro (UFRJ) e outro em São Paulo (USP). Estes grupos contaram com a participação de diversos pesquisadores americanos e ingleses e foram criados com base em acordos científicos bilaterais CNPqNAS (Conselho Nacional de Pesquisas e Desenvolvimento, do Brasil e National Academy of Sciences, dos Estados Unidos), possibilitando a conjunção de esforços entre estes pesquisadores, que foram temporariamente fixados através de bolsas e, posteriormente em muitos casos, como professores em nossas universidades, e os poucos professores-pesquisadores que havia à época, contribuindo de forma decisiva para o desenvolvimento da área.

Os anos 70 presenciaram um notável crescimento e renovação dos quadros das universidades públicas brasileiras e a consolidação da pós-graduação em química. Cabe lembrar que o CNPq e a CAPES comemoraram, no ano passado, 50 anos de existência, desempenhando papel fundamental no fomento das atividades de ensino

\footnotetext{
*e-mail: cegvito@vm.uff.br
}

de pós-graduação e pesquisa no país. Entretanto, em 1977, data da fundação da SBQ, o mapa da química orgânica no Brasil era concentrado basicamente no sudeste do Brasil. Este cenário já contabilizava a participação dos primeiros professores e pesquisadores egressos do exterior, com formação especializada em química orgânica.

No presente artigo, os autores, representando a área de Química Orgânica neste volume comemorativo, homenageiam a todos que nestes 25 anos contribuíram para o engrandecimento da SBQ. O artigo procura dar um panorama geral da evolução da Química Orgânica através dos trabalhos apresentados nas reuniões da SBQ nos últimos vinte e cinco anos. O desenvolvimento da área também foi avaliado através dos trabalhos enviados aos Encontros de Síntese Orgânica (Brazilian Meeting on Organic Synthesis).

Entretanto, como preâmbulo a esta análise, é pertinente discorrer sobre o papel da Química, em especial da Química Orgânica, no contexto sócio-econômico e a sua evolução no cenário internacional, apontando as fronteiras da área neste início de século.

\section{CIÊNCIA E DESENVOLVIMENTO SOCIAL}

"O estado promoverá e incentivará o desenvolvimento científico, a pesquisa e a capacidade tecnológica." (Caput do artigo 218 da Constituição do Brasil)

A Química é um importante instrumento para o desenvolvimento sócio-econômico de um país ${ }^{1}$. Este fato deve sempre ser relembrado aos nossos dirigentes políticos, já que o desenvolvimento da C\&T aumenta a produção e melhora a qualidade de vida da população. A Química tem contribuído significativamente neste sentido, propiciando o desenvolvimento de novos medicamentos, defensivos agrícolas, novos materiais para aplicações médicas e eletrônicas dentre outros, cujos benefícios foram plenamente absorvidos pela sociedade. A Química está completamente inserida no panorama econômico de qualquer país, por se tratar de área de grande importância econômica da balança comercial, e no Brasil é geradora de milhares de empregos e responsável por parte significativa do PIB.

Cabe considerar, adicionalmente, que a Química Orgânica vem expandindo as fronteiras de suas áreas de atuação. Em um instigante 
artigo publicado em 1991, intitulado "Organic Chemistry, Where Now?"2, o Prof. Dieter Seebach apontava quais seriam, na sua opinião, os caminhos para a Química Orgânica no futuro próximo. Um maior grau de interação das Ciências Biológicas com a Química foi apontado como um fator importante para o fortalecimento da disciplina, o que permitiria o avanço no conhecimento biológico em nível molecular. A produção de moléculas funcionais, o desenvolvimento de novos processos catalíticos e a descoberta de novas reações químicas também foram apontados como desafios de fronteira a serem vencidos. Em sua opinião a descoberta de novas reações estaria limitada à área da química dos metais de transição, assim como uma química "mais limpa" seria também uma aspiração tanto dos químicos quanto da comunidade em geral. Em boa medida, todas essas previsões acabaram tornando-se realidade e atualmente têm servido como diretriz a novos avanços científicos.

De uma forma geral a Ciência Brasileira, incluindo-se a Química, já demonstrou a sua capacidade de promover desenvolvimento de diferentes setores nacionais, como por exemplo: a prospecção e a extração de petróleo das profundezas do mar e, mais recentemente, o mapeamento dos genomas da Xylella fastidiosa e Xanthomonas citri ${ }^{3}$.

Num momento da história da humanidade em que o desenvolvimento tecnológico representa, como nunca, supremacia econômica, a Química tem grandes desafios e contribuições a dar. Os conhecimentos científicos e tecnológicos destacam os países mais avançados e economicamente mais fortes. $\mathrm{O}$ seu emprego como instrumento de desenvolvimento, juntamente com um avanço cultural e educacional, deve ser encarado como um agente responsável na transformação da rede social ${ }^{4}$. Em recente artigo, Moura ${ }^{5}$ mostra, de forma bem clara, as relações entre inovação tecnológica e o avanço científico.

Atualmente, a diferença entre o tempo de uma descoberta científica e a sua aplicação na sociedade, sob forma de um produto tecnológico, foi encurtado significativamente. Praticamente não há separação entre produção científica e tecnológica, e novos empreendimentos são criados a partir das mais recentes descobertas, com velocidade proporcional às necessidades ou capacidade de absorção dos mercados. Destas observações depreende-se uma conclusão, que não é nova, mas muito importante: o país precisa de uma política para C\&T clara e definida para enfrentar os novos desafios ao desenvolvimento nacional.

\section{A QUÍMICA ORGÂNICA NO MUNDO}

Entre meados do séc. XIX e o início do séc. XX somente algumas poucas substâncias orgânicas haviam sido obtidas em forma relativamente pura e a determinação de suas estruturas representou um grande desafio para a então emergente Teoria Estrutural. Estas substâncias (alcalóides isolados de poções medicamentosas, ácidos carboxílicos e produtos voláteis de natureza terpênica) isoladas principalmente a partir de plantas, constituíam a única fonte de substâncias orgânicas à época ${ }^{6,7}$. Foi também nesta época que começaram a aparecer os primeiros relatos sobre a preparação de produtos naturais em laboratório. O desenvolvimento da carboquímica e da petroquímica, no início do século passado, disponibilizou para os químicos um amplo leque de novas matérias-primas e possibilitou a implantação de indústrias químicas. A criação da indústria química Bayer na Alemanha, com a produção industrial de corantes sintéticos, é um marco do processo de industrialização.

O grande avanço experimentado pela síntese orgânica a partir de meados do séc. XX, resultado do avanço experimentado na compreensão dos mecanismos de reação e análise conformacional, possibilitou uma maior compreensão da reatividade química. A rápida expansão dos métodos espectroscópicos, a partir dos anos 60, possibilitou a análise rotineira de estruturas químicas de forma não destrutiva, dando uma outra dinâmica ao estudo das reações químicas. Todas as áreas da Química Orgânica se beneficiaram enormemente destes avanços.

Com o avanço da síntese orgânica, os produtos sintéticos começam a ganhar em diversidade e em competitividade em relação aos produtos naturais em diversos setores industriais. No setor farmacêutico, por exemplo, predomina atualmente o uso de insumos sintéticos enquanto que o uso de produtos naturais predominou na primeira metade do século passado.

\section{A SÍNTESE ORGÂNICA}

\begin{abstract}
“... a síntese evoluiu ao ponto que ela precisa ser praticada de forma a transcender a curiosidade intelectual, desafio ou outras razões para uma conquista. Para os cientistas acadêmicos, a síntese de um produto natural deve ser o fórum adequado para a descoberta de novos métodos sintéticos e testar sua aplicabilidade". (S. Hannesian ${ }^{9}$ )
\end{abstract}

Historicamente ${ }^{10}$, a síntese orgânica tem se desenvolvido de acordo com as necessidades e a curiosidade humana. Dentre os descobrimentos que marcaram época e que podem ser considerados como fundamentais no desenvolvimento da Química Orgânica destacamse as sínteses da uréia por Frederich Wöhler em 1828, a partir do cianato de amônio e a síntese do corante mauveína por Willian $\mathrm{H}$. Perkin em $1856^{11}$. O feito de Wöhler marca não somente o fim da teoria da força vital, fervorosamente defendido por vários químicos influentes da época, como também o nascimento da Química Orgânica Sintética como ramo da Química Orgânica. Já o feito de Perkin, uma tentativa frustrada de preparar quinina a partir da anilina, abriu caminho para o desenvolvimento racional e científico da Química Medicinal e estabeleceu uma forte associação entre Química Orgânica e Química Medicinal, que permanece até os dias de hoje. De fato, entre os principais alvos escolhidos pelos químicos orgânicos sintéticos ao longo dos anos encontram-se produtos cuja complexidade estrutural, potentes e diversificadas atividades biológicas/ farmacológicas despertaram enorme interesse científico e medicinal, como por exemplo os esteróides, as prostaglandinas, os antibióticos $\beta$-lactâmicos, substâncias macrocíclicas com ação antibiótica e anti-câncer, entre outros exemplos.

São muitos os mestres da síntese orgânica e discutir todas estas contribuições foge do escopo deste trabalho. Foram escolhidos exemplos que nos pareceram significativos, o que implica em um sem número de importantes omissões. Cabe considerar que uma parte importante dos esforços sintéticos desenvolvidos pela comunidade acadêmica e setor produtivo visam a preparação de fármacos ${ }^{12}$ e não foram considerados neste artigo.

Uma das definições mais fiéis do que representa a síntese orgânica, dentro de um contexto científico e do espírito humano, foi elaborada por E. J. Corey, detentor do prêmio Nobel de Química de 1990 e criador do "Disconnection Approach", ferramenta de grande valor usada rotineiramente para o planejamento sintético: "Um químico sintético é mais que um estrategista com lógica. Ele é um explorador altamente influenciado na arte de especular, imaginar e também criar. Estes elementos dão a ele um toque de artista o qual dificilmente poderia ser incluído nos compêndios dos princípios básicos de síntese. Estes elementos são reais e extremamente importantes"13.

A síntese orgânica se desenvolveu mais rapidamente na segunda metade do séc. XX, devido à descoberta de muitas reações novas, principalmente reações de formação da ligação C-C e ao avanço dos reagentes organometálicos preparados a partir de metais de transição. Podemos dividir este período em décadas ou eras: 
1- Década de 50: Período das sínteses totais orientadas pelas estruturas. Sínteses hoje consideradas clássicas e que tinham também como sub-objetivo a busca de novos conhecimentos mecanísticos a respeito das reações químicas. Foi em 1954 que R. B. Woodward publicou a primeira síntese total de um produto natural, a estricnina.

2- Década de 60: Período do desenvolvimento de metodologias sintéticas de enorme potencial (Wittig, organocupratos), da incorporação das estratégias e conceitos no planejamento sintético. Novas moléculas-alvo, de alta complexidade, são preparadas em laboratório, como por exemplo as prostaglandinas e vários terpenóides. Iniciam-se os processos enantiosseletivos catalisados por metais de transição contendo ligantes quirais.

3-Década de 70: Período com ênfase em metodologias e estratégias baseadas em processos biossintéticos (sínteses biomiméticas) e no desenvolvimento de novos reagentes organometálicos. Época marcada também pelo desenvolvimento acentuado no controle estereoquímico das reações orgânicas. Desenvolvimento racional dos primeiros auxiliares de quiralidade, que se estende e se aprimora na década de 80, possibilitando versões enantiosseletivas para diversas reações de oxidação, redução e, essencialmente, todas as reações de formação de ligações C-C.

4- Década de 80: Década com ênfase no desenvolvimento de reações enantiosseletivas envolvendo catalisadores quirais, tais como a epoxidação de Sharpless, reação aldólica, a hidrogenação catalítica empregada na síntese da L-DOPA pela Monsanto e dos catalisadores quirais contendo o ligante BINAP, desenvolvido por R. Noyori. O prêmio Nobel de Química de 2001 faz justiça ao enorme avanço científico proporcionado por essas tecnologias, agraciando os químicos William S. Knowles, R. Noyori e K. Barry Sharpless, pioneiros no uso da catálise assimétrica.

5- Decada de 90: Continua a ênfase em síntese e catálise assimétrica, com a preparação de moléculas alvo de grande grau de complexidade estrutural. Com o conhecimento da estrutura do sítio ativo de enzimas e proteínas receptoras presentes nas membranas celulares, $o$ desenho planejado de novos bioligantes e suas interações com as moléculas alvo constituíram-se numa importante atividade onde colaboraram químicos orgânicos sintéticos e químicos medicinais. Nesta década, despontam estudos envolvendo estruturas supramoleculares e os fenômenos de reconhecimento molecular e auto-agregação, propriedades presentes nas moléculas biológicas que passam a ser mimetizados em laboratório. No final desta década começam a aparecer pesquisas envolvendo diversidade molecular e química combinatorial $^{14}$.

Ao longo da história muitas sínteses totais de substâncias complexas marcaram o desenvolvimento da área de síntese orgânica, principalmente porque muitas destas sínteses trouxeram à luz novas metodologias (Tabela 1). Por exemplo, já em 1904 a síntese do $\alpha$ terpineol (W. H. Perkin) e em 1917 a síntese da tropinona (R. Robinson) revelavam uma sofisticada abordagem retrossintética. A síntese de um alvo complexo como a quinina em 1944, por Robert Woodward e William von Eggers Doering, pode ser considerada como uma das grandes realizações da síntese orgânica na primeira metade do século. Entretanto, um fato curioso na síntese da quinina, relatada por Woodward e Doering, é que ela foi realizada de maneira "formal" e não total como muitos imaginam até então. A única síntese total estereosseletiva da (-)-quinina foi relatada bem recentemente por Gilbert Stork e colaboradores ${ }^{15,16}$

Outros eventos importantes na síntese orgânica estão mostrados no quadro a seguir. Deve-se ressaltar que, atualmente, a evolução da síntese alcança níveis surpreendentes, como pode ser comprovada com as recentes sínteses da palitoxina realizada por Y. Kishi e colaboradores em $1982^{17}$ e do taxol ${ }^{18}$, realizada concomitantemente pelos grupos dos professores R. A. Holton ${ }^{19}$ e K.C. Nicolaou ${ }^{20}$. A sínte- se do taxol teve uma disputa extremamente controversa quanto ao detentor do mérito de "primeira síntese total" e envolveu os grupos dos profs. Holton e Nicolaou ${ }^{21,22}$.

Tabela 1. Sínteses clássicas que marcaram a evolução da área

\begin{tabular}{ll}
\hline Síntese do Cicloctatetraeno & R. Willstate (1915) \\
Síntese da Tropinona & R. Robinson (1917) \\
Síntese da Quinina & R.B. Woodward (1945) \\
Síntese da Penicilina & J.C. Sheehan (1957) \\
Síntese da Reserpina & R.B. Woodward (1958) \\
Síntese do Dodecaedrano & L. Paquete (1963)
\end{tabular}

A Química Orgânica sintética nas duas últimas décadas mostrou que é possível a preparação de produtos naturais, ou mesmo não naturais, bastante complexos, tarefa que exige uma boa dose de criatividade, inteligência e perseverança $\mathrm{a}^{23}$. O contínuo desenvolvimento de novas metodologias sintéticas e o aperfeiçoamento constante das técnicas de análise orgânica, conjugados com uma grande variedade de reações e metodologias, associadas aos avanços das técnicas instrumentais, permitiu a preparação de moléculas com alto controle da enantiosseletividade. Foram desenvolvidas algumas sínteses espetaculares, e em alguns casos únicas, como por exemplo, a síntese da vitamina $\mathrm{B}_{12}$ (Tabela 2$)^{24}$. Pode-se perceber que, para atingir a síntese de produtos naturais complexos, passou-se por fases como as dos esteróides, terpenóides, alcalóides e prostanóides. Atualmente tem-se buscado as sínteses de diversos agentes anticancerígenos das famílias dos macrolídeos de origem marinha.

Tabela 2. Algumas sínteses selecionadas de alta complexidade

\begin{tabular}{ll}
\hline Síntese da Vitamina B & R. B. Woodward (1976) \\
Síntese da Palitoxina & Y. Kishi (1982) \\
Síntese da Brevetoxina & K. C. Nicolaou (1995) \\
Síntese do Taxol & R. A. Holton e K.C. Nicolaou (1994) \\
\hline
\end{tabular}

Algumas substâncias foram sintetizadas dezenas de vezes. Por exemplo, a (-)-quadrona foi sintetizada 16 vezes, por rotas totalmente diferentes, sendo 13 na forma racêmica $(+/-)$, duas para o enantiômero $(+)$ e apenas uma para o enantiômero com a configuração natural (-).

A procura por alternativas sintéticas mais viáveis levou vários pesquisadores a proporem diferentes rotas sintéticas para uma mesma molécula. Obviamente o grande número de sínteses para uma mesma substância, demonstra que, em geral, há um interesse econômico por ela. Na maioria dos casos procura-se obter a substância no maior rendimento global possível e no menor número de etapas. Por exemplo, a estricnina, um importante alcalóide, teve a sua primeira síntese realizada em 27 etapas ${ }^{25}$ e atualmente já se pode realizá-la em 19 etapas (Figura 1). O objetivo de diminuir o número de etapas desta e de muitas outras sínteses continua como um dos grandes objetivos da Química Orgânica sintética, cuja grande preocupação

P. Magnus (27 etapas, 1992)

L. Overman (20 etapas, 1993)

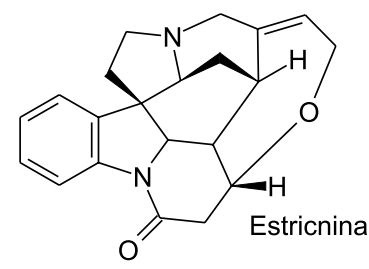

R.B. Woodward (27 etapas 1954$)$

Figura 1. Algumas sínteses da estricnina 
ainda continua sendo a busca da melhor rota para se alcançar um determinado alvo sintético.

Todo este avanço da Química Orgânica pode ser traduzido na fascinante síntese da palitoxina $(\mathbf{1})^{26}$ realizada por Y. Kishi e colaboradores $^{27}$, cuja estrutura contém 64 centros quirais e 7 elementos de estereoquímica geométrica, podendo gerar $2^{71}$ estereoisômeros (Figura 2).

Desde a década de 80 os organometálicos de transição desempenham um papel fundamental na formação de ligação C-C, principalmente com os elementos paládio, níquel, ferro, cromo, molibdênio, manganês, ósmio, zircônio e rutênio, dentre outros ${ }^{28}$. Várias reações baseadas nestes elementos foram descobertas. Algumas mais relevantes são: as epoxídações assimétricas com titânio (epoxidação de Sharpless) e manganês (epoxidação de Jacobsen), as diidroxilações assimétricas com ósmio (diidroxilação de Sharpless), o acoplamento de Stille envolvendo reagentes organoestanho e paládio zerovalente; as adições de organocupratos; as reações de acoplamento envolvendo organopaládio (Wacker, Heck, Suzuki, Sonogashira, Negishi, Kumada, etc..), as reações de formações de anéis via reações por metatesis de olefinas (catalisador de Shrock e Grubbs), as cicloadições catalisadas por $\mathrm{Co}, \mathrm{Rh}, \mathrm{Ru}$ ou Mo; as reações inserções de diazo compostos catalisadas por ródio ${ }^{29}$ e a resolução cinética com catalisadores quirais de Shrock e Grubbs. Não menos importantes foram os avanços nas químicas de outros elementos como: silício $^{30}$, mercúrio $^{31}$, boro ${ }^{32}$, tálio $^{33}$, telúrio ${ }^{34}$ e selênio ${ }^{35}$.

Enormes avanços foram obtidos nas últimas décadas nas reações de formação das ligações C-C e também nas transformações de grupos funcionais. Estas novas técnicas aumentaram a eficiência destas transformações e simplificaram bastante as condições experimentais. Podemos citar, dentre muitas: a catálise por transferência de fases; as reações suportadas ou catalisadas por polímeros (orgânicos e inorgânicos $)^{36}$; as reações em fase sólida; as reações eletroquímicas ${ }^{37}$; as reações com alta pressão; o uso de enzimas e anticorpos monoclonais; o uso de ultrassom (sonoquímica); o uso de microondas e reações fotoquímicas; as termólises a alta temperatura em curto espaço de tempo; etc.

A evolução da Química Orgânica mundial, traduzida em uma forma refinada pelas sínteses orgânicas, de uma forma geral repre- senta também o desenvolvimento do perfil sócio-econômico da Química. As descobertas científicas nos setores industriais químicos e farmacêuticos têm levado certas empresas para posições de liderança nos mercados internacionais. Como exemplo pode-se citar a criação de diversas empresas voltadas para as sínteses em fase sólida, sínteses enantiosseletivas e os métodos de síntese automatizados, particularmente as sínteses de polipeptídeos pelo processo de Merrifield.

\section{A QUÍMICA ORGÂNICA NO BRASIL NOS ÚLTIMOS 25 ANOS}

\begin{abstract}
"A química cria seus próprios temas. Esta habilidade criativa, similar à arte, essencialmente a distingue de outras ciências naturais" M. Berthelot (1827-1907).
\end{abstract}

Desde a fundação da SBQ, a área de Química Orgânica sempre foi uma das mais ativas dentro da Sociedade, pois na sua primeira reunião anual, em 1978 e ainda associada às reuniões anuais da SBPC, teve cinco seções científicas, a saber: Química Analítica, Físico-Química, Química Inorgânica, Química Orgânica e Química de Produtos Naturais. Posteriormente outras seções foram criadas, sugerindo que no futuro as áreas clássicas seriam desmembradas em divisões científicas.

A área de Química Orgânica decidiu-se pela criação da Divisão de Síntese Orgânica, que teve como primeiro diretor o saudoso Prof. José Tércio B. Ferreira. Posteriormente, por decisão dos seus membros, em 1996, a Divisão de Síntese Orgânica teve seu nome modificado para Divisão de Química Orgânica, pois assim poderia representar de forma mais coesa um universo maior de pesquisadores.

$\mathrm{Na}$ tentativa de traçar um quadro evolutivo da área de Química Orgânica na SBQ, foram consultados os dados contidos nos Livros de Resumo das reuniões anuais a partir de 1978. A partir desses dados foram criados alguns indicadores representativos das diversas atividades e trabalhos apresentados nas reuniões anuais da SBQ e nos BMOS. Esses indicadores envolvem os aspectos a seguir. Indicadores I1: estudos de mecanismos, investigação de processos, derivatizações e transformações diretas e/ou conversões sintéticas;

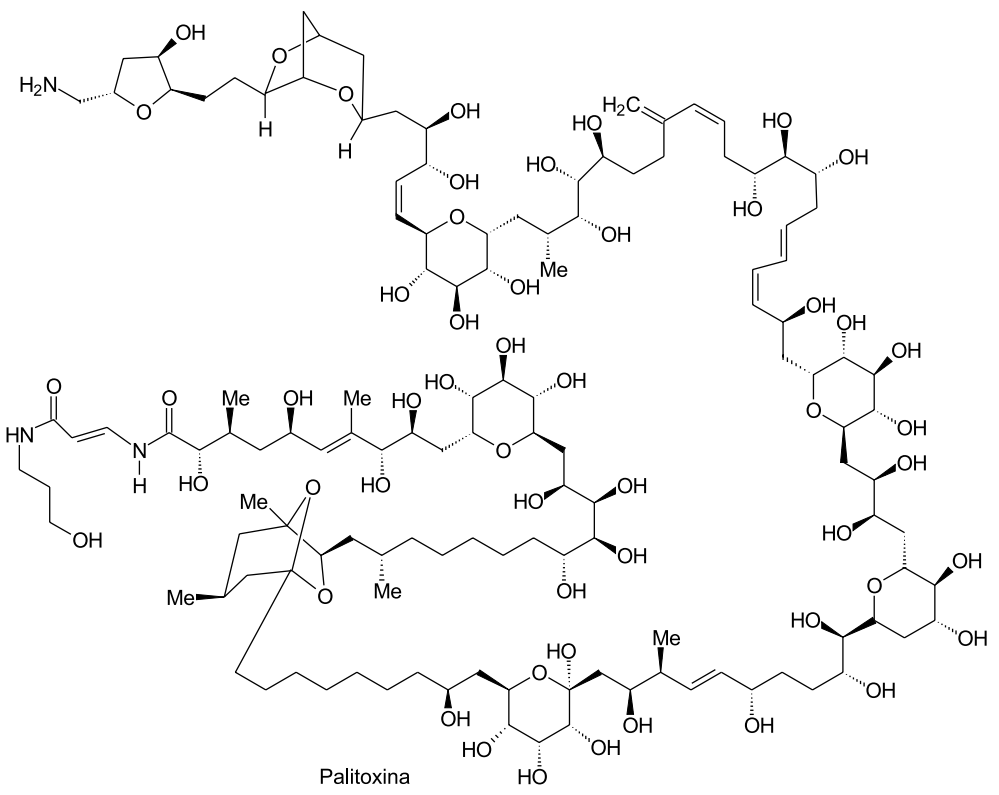

Figura 2. Estrutura da Palitoxina isolada de Palythoa tuberculosa 
métodos de separação cromatográfica; estudos cinéticos; medidas espectroscópicas; estudos comparativos, etc. ${ }^{38}$; Indicadores I2: sínteses em etapas múltiplas envolvendo mais do que duas etapas sintéticas em seqüência; Indicadores I3: desenvolvimento de novas metodologias, englobando novos métodos sintéticos e/ou uma nova abordagem em processo sintético envolvendo até duas etapas de síntese ${ }^{39}$; Indicadores I4: sínteses envolvendo aspectos de estereosseletividade $^{40,41}$; Indicadores I5: desenvolvimento de metodologias envolvendo aspectos de estereosseletividade, como por exemplo o uso de auxiliares quirais, catálise assimétrica, reagentes quirais, etc.; Indicadores I6: métodos biocatalíticos envolvendo todos os trabalhos utilizando enzimas tanto no aspecto sintético como mecanístico.

Apesar de existirem outros indicadores possíveis, acreditamos que estes demonstrem como a Química Orgânica evoluiu no país, sob o olhar das reuniões anuais da SBQ.

$\mathrm{Na}$ Tabela 3 (Figura 3) estão resumidos os dados encontrados neste levantamento. Observa-se claramente que do ano de 1979 para o ano 2001 houve um gradual aumento no número de resumos apresentados nas R.A. na área de Química Orgânica. Apesar do crescimento parecer pouco expressivo, nota-se que durante estes 25 anos várias novas divisões foram criadas, como Fotoquímica, Química Medicinal, Química Teórica e Química Analítica. Por exemplo, no ano de 1982 foram criadas as seções de Química Aplicada e Química Ambiental. Neste ano o número de resumos caiu para 85 , sendo que no ano de 1981 foi de 127 . No ano de 1984 desapareceram as a seções de Química Ambiental e Instrumentação e foi criada a seção de Química Teórica. De uma certa forma, todas estas seções estiveram dentro da área de Química Orgânica e agora atuam de forma independente. Logo, o crescimento da Química Orgânica foi muito além do esperado. Em alguns anos, como em 2001, há um decréscimo do número total de resumos devido à concorrência do BMOS, porém se somarmos o número de trabalhos na R.A. da SBQ (2001) com o do BMOS (2001) observa-se que ultrapassa a 300. Mesmo excluindo-se os trabalhos internacionais do BMOS, observa-se que a tendência de crescimento continua positiva.

Em termos químicos, o perfil dos trabalhos também mudou consideravelmente. De 1979 para 2001, observa-se pelo Indicador I1, que a área era dominada por trabalhos envolvendo o desenvolvimento de processos, estudos e determinações estruturais por métodos espectroscópicos, cinéticas das reações e vários outros aspectos mecanísticos. Gradualmente, as duas outras macro linhas de pesqui- sas, representadas pelos Indicadores I2 e I3, foram crescendo e, atualmente, representam o perfil predominante da área. A partir de 1984, começaram a aparecer trabalhos em síntese assimétrica de forma sistemática, o que é aparente pelos Indicadores 14 e I5, apesar do primeiro trabalho em síntese assimétrica ter sido publicado em $1979^{42}$. Vários trabalhos apresentados ao longo dos anos mostraram que a biocatálise, utilizando microorganismos do solo brasileiro, pode representar uma fonte valiosa e promissora de materiais quirais. É importante ressaltar a preocupação dos pesquisadores da área de síntese com a quiralidade, ou seja, com a preparação de substâncias enantiomericamente puras ou enantiomericamente enriquecidas, que possam ser utilizadas como matéria-prima em processos sintéticos ou biotecnológicos.

Tabela 3. Levantamento dos resumos apresentados pela área de Química Orgânica nas RASBQ entre os anos 1979-2001

\begin{tabular}{lrrrrrrr}
\hline ANO & I1 & I2 & I3 & I4 & I5 & I6 & Total \\
\hline 2001 & 52 & 50 & 25 & 8 & 4 & 6 & 145 \\
2000 & 63 & 50 & 49 & 25 & 03 & 10 & 200 \\
1999 & 51 & 53 & 22 & 37 & 03 & 13 & 179 \\
1998 & 64 & 37 & 23 & 02 & 02 & 16 & 144 \\
1997 & 68 & 34 & 49 & 05 & 00 & 08 & 164 \\
1996 & 104 & 21 & 26 & 20 & 02 & 06 & 179 \\
1995 & 91 & 44 & 27 & 13 & 09 & 05 & 189 \\
1994 & 115 & 30 & 22 & 13 & 08 & 03 & 191 \\
1993 & 97 & 19 & 49 & 23 & 5 & 3 & 198 \\
1992 & 105 & 13 & 53 & 5 & 6 & 6 & 189 \\
1991 & 89 & 11 & 45 & 15 & 6 & 2 & 177 \\
1990 & 52 & 9 & 28 & 4 & 7 & 1 & 103 \\
1989 & 65 & 12 & 49 & 5 & 6 & 0 & 137 \\
1988 & 40 & 9 & 52 & 2 & 13 & 1 & 117 \\
1987 & 66 & 26 & 74 & 3 & 11 & 1 & 181 \\
1986 & 59 & 28 & 42 & 3 & 3 & 1 & 135 \\
1985 & 48 & 27 & 47 & 2 & 3 & 0 & 127 \\
1984 & 48 & 19 & 37 & 5 & 1 & 0 & 110 \\
1983 & 3 & 18 & 32 & 0 & 0 & 0 & 83 \\
1982 & 49 & 17 & 19 & 0 & 0 & 0 & 85 \\
1981 & 64 & 20 & 43 & 0 & 0 & 0 & 127 \\
1980 & 83 & 13 & 30 & 0 & 0 & 0 & 126 \\
1979 & 71 & 23 & 18 & 1 & 0 & 0 & 113 \\
\hline & & & & & & &
\end{tabular}

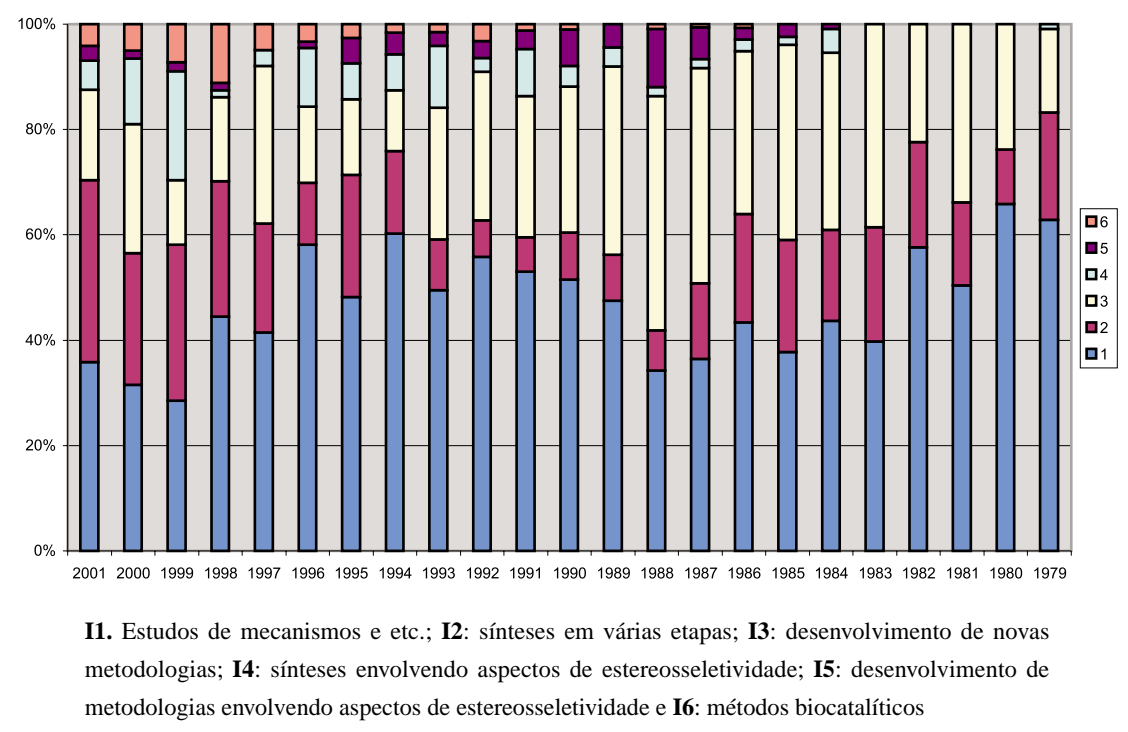

Figura 3. Distribuição dos resumos de Química Orgânica nas RASBQ entre os anos de 1978-2001 conforme os indicadores I1-I6 
Da mesma forma que nas reuniões anuais, o número de resumos em síntese orgânica continua aumentando nos BMOS (Tabela 4, Figura 4), indicando claramente o vigor da síntese dentro do contexto da Química Orgânica. A análise conjunta dos dados indica que a atividade de desenvolvimento de métodos em síntese (I3) foi majoritária ao longo dos últimos 14 anos, em detrimento das investigações mecanísticas e dos estudos espectroscópicos. A segunda macro linha de pesquisa mais produtiva foi a de sínteses totais (I2), mas as atividades em sínteses totais assimétricas (I4), catálise assimétrica (I5) e enzimática (I6) vêm se consolidando como as novas fronteiras da Química Orgânica no Brasil.

Tabela 4. Levantamento dos resumos nos "Brazilian Meeting on Organic Synthesis" entre os anos 1987-2001

\begin{tabular}{rrrrrrrr}
\hline ANO & I1 & I2 & I3 & I4 & I5 & I6 & Total \\
\hline 2001 & 0 & 47 & 67 & 38 & 23 & 8 & 183 \\
1998 & 10 & 37 & 79 & 27 & 39 & 4 & 196 \\
1996 & 13 & 20 & 83 & 19 & 23 & 3 & 161 \\
1994 & 4 & 21 & 52 & 12 & 17 & 4 & 110 \\
1992 & 6 & 12 & 47 & 18 & 19 & 4 & 110 \\
1990 & 0 & 28 & 33 & 5 & 9 & 3 & 78 \\
1989 & 0 & 36 & 51 & 8 & 8 & 2 & 105 \\
1987 & 12 & 12 & 25 & 1 & 3 & 0 & 43 \\
\hline
\end{tabular}

\section{QUÍMICA E MEIO AMBIENTE}

Em princípio, a Química Orgânica sempre procurou entender a forma e a função das moléculas, assim como compreender como elas interagem. Porém, atualmente é uma área que não está mais restrita aos seus temas clássicos. Novas interfaces vêm cada vez mais sendo estudadas na Química Orgânica, principalmente voltadas ao estabelecimento de novos processos. Dentre as áreas que têm recebido contribuições importantes da Química Orgânica para seu avanço estão a catálise, biotecnologia, ciência dos materiais, genética química, química farmacêutica, química ambiental, nanotecnologia, biologia, genômica e conhecimento molecular, etc. Entretanto, em paralelo a todo este desenvolvimento científico, a maioria dos processos são antigos e/ou pouco econômicos. Do ponto de vista ambiental, muitos desses processos produzem uma grande quantidade de lixo químico. Esse aspecto traz uma visão bastante negativa para a Química perante a sociedade. As agressões ao meio ambiente são uma realidade que não se pode esconder ${ }^{43}$.

Devido a esta face negativa da Química Orgânica, esta tem sido rotulada pelos ambientalistas, e pela parte menos esclarecida da população, como a principal causadora dos grandes problemas ambientais. De fato, em algumas ocasiões as indústrias químicas, principalmente a de produtos farmacêuticos, produzem uma quantidade considerável de subprodutos não aproveitáveis. Só, recentemente, muitas dessas empresas passaram a se preocupar com os rejeitos gerados durante os processos de produção. A Tabela 5 mostra claramente que a indústria farmacêutica, baseada fundamentalmente em síntese orgânica gera cerca de $25-100 \mathrm{Kg}$ de lixo químico para cada $\mathrm{Kg}$ do produto final ${ }^{44,45}$.

Tabela 5. Relação entre segmento industrial e produção de lixo químico

\begin{tabular}{lcc}
\hline Segmento Industrial & $\begin{array}{c}\text { Produção Bruta } \\
\text { (ton) }\end{array}$ & $\begin{array}{c}\text { kg lixo/kg } \\
\text { de produto }\end{array}$ \\
\hline Refinamento de óleos & $10^{6}-10^{8}$ & $\sim 0,1$ \\
Ind. Química Pesada & $10^{4}-10^{6}$ & $<1-5$ \\
Especialidade Química & $10^{2}-10^{4}$ & $5-50$ \\
Ind. Farmacêutica & $10^{1}-10^{3}$ & $25-100$ \\
\hline
\end{tabular}

Como para o público em geral a Química é sinônimo de chaminés fumegantes e rios envenenados, pesquisas devem ser desenvolvidas no sentido de minimizar não só os riscos dos processos e efluentes, como também melhorar a qualidade de vida da população e garantir a qualidade dos produtos químicos para o consumidor. Neste caso, há necessidade de mudança para um novo paradigma, onde a eficiência do processo químico deve estar baseada também em valores ambientais ${ }^{46}$. É necessário o uso de conhecimentos químicos para se prevenir a poluição ambiental, seja através do planejamento de processos químicos, seja através do tratamento adequado dos resíduos gerados. A racionalização do processo e a economia de átomos (atom economy) devem ser considerados como elementos quase tão importantes quanto o rendimento químico puro e simples. No Esquema 1

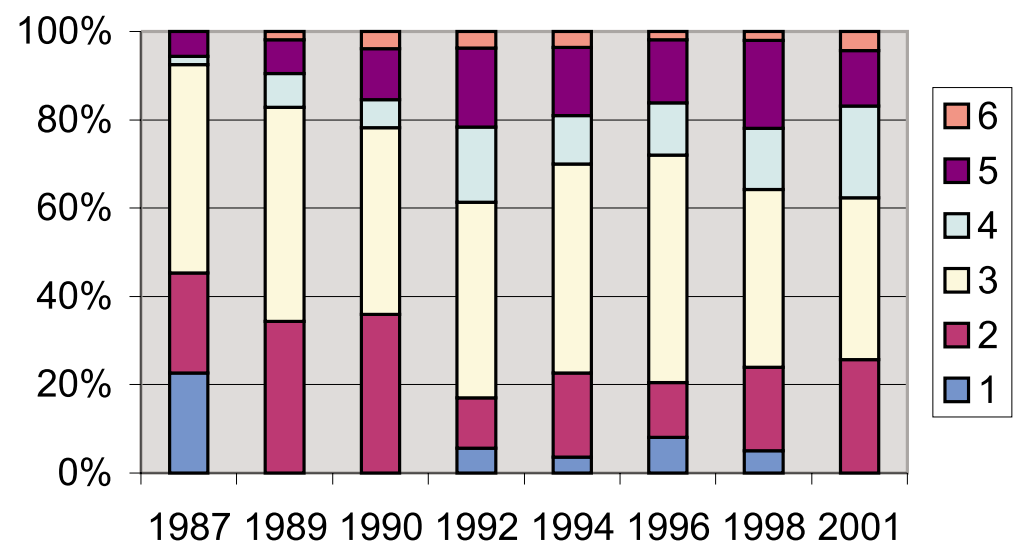

I1: Estudos de mecanismos e etc.; I2: sínteses em várias etapas; I3: desenvolvimento de novas metodologias; I4: sínteses envolvendo aspectos de estereosseletividade; I5: desenvolvimento de metodologias envolvendo aspectos de estereosseletividade e I6: métodos biocatalíticos 


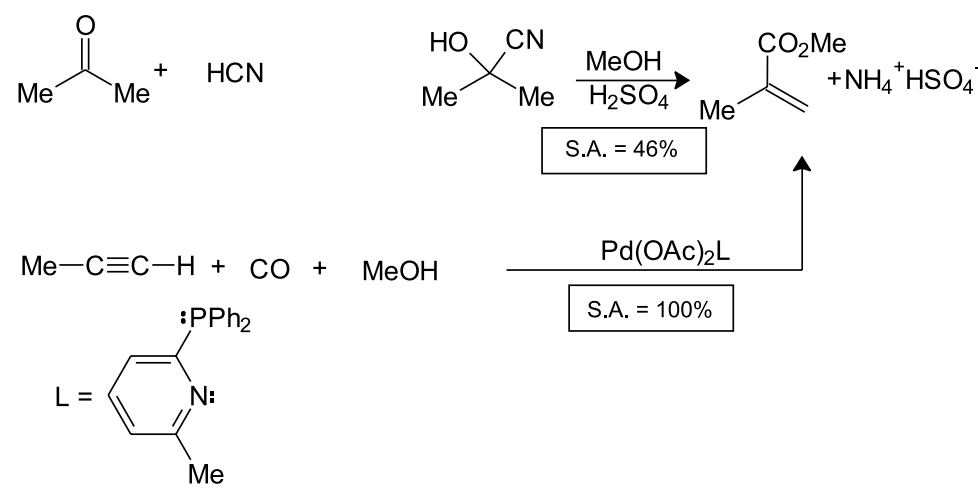

Esquema 1. Processos de obtenção de metacrilato de metila com diferentes avaliações em termos de economia de átomos

pode-se observar claramente a diferença na economia de átomos entre dois processos de oxidação, onde o processo catalítico utilizando oxigênio como catalisador tem um melhor desempenho ${ }^{47}$.

$\mathrm{O}$ modelo econômico que visa fundamentalmente o lucro e a acumulação de riquezas a curto prazo é uma das barreiras que impedem uma consciência ambiental. Para avançar nas questões ambientais que envolvem a Química Orgânica será necessário uma Química de alta qualidade, onde se deve pensar em elementos como a eliminação de solventes agressivos e o uso de reações catalíticas, o uso de reações em fase sólida, emprego de biocatálises, uso de solventes supercríticos, minimização de resíduos, novos processos de separação, uso de biomassas renováveis, aproveitamento de líquidos iônicos, reações em sistemas bifásicos, integração de processos e a educação dos químicos em química ambiental. A utilização de água como solvente, aparentemente é uma alternativa atraente, pois a água é um solvente com poucos riscos ambientais ${ }^{48}$. Prevenir a formação de rejeitos deve ganhar mais prioridade em processos industriais, pois a ação de remover e/ou eliminar esses resíduos é dispendiosa.

\section{CONCLUSÃO}

A área de Química Orgânica foi o berço de diversas divisões da SBQ, no entanto as divisões clássicas da Química tendem a desaparecer e a gerar novas interfaces. Os atuais desafios científicos exigem que os cientistas procurem interfaces específicas com a biologia celular, biotecnologia, ecologia, bioquímica, genômica, genética, nanotecnologias, fenômenos de superfície, etc, de onde certamente surgirão as novas descobertas científicas de grande relevância para a Humanidade. Com todas estas possibilidades de diversificação e novas interfaces, o número de resumos apresentados pela área de Química Orgânica nas RA continua aumentando, indicando claramente o seu potencial dentro do contexto químico nacional. A análise conjunta dos dados da área de Química Orgânica dos últimos 25 anos indica que a atividade em síntese orgânica foi a que mais evoluiu, tendo ocorrido uma retração nas investigações mecanísticas e nos estudos espectroscópicos, atividades prioritárias nos anos 70. Uma boa parte das comunicações atuais em química orgânica estão relacionadas ao desenvolvimento ou aplicações de metodologias, sendo a atividade em sínteses totais ainda minoritária. A despeito de um crescente aumento na interface das pesquisas, chama atenção a pequena quantidade de trabalhos na área de catálise, em especial em catálises assimétricas.

A Química Orgânica Sintética nas duas últimas décadas no Brasil mostrou que pode trabalhar com a preparação de produtos naturais e não naturais complexos, apesar das dificuldades na obtenção de recursos e do tempo necessário para se realizar a importação de reagentes. Entretanto, houve um contínuo aperfeiçoamento de novas metodologias sintéticas, assim como avanços muito significativos nas técnicas instrumentais, que permitirão no futuro, sínteses de moléculas cada vez mais complexas e com alto grau de eficiência e controle da estereosseletividade.

Para que possamos credenciar a Química Orgânica, e de uma forma geral a Química no Brasil, é preciso não somente avançar na direção de novos conhecimentos científicos, mas também oferecer uma formação científica sólida aos nossos estudantes de graduação e pós-graduação, incluindo ainda a formação e a educação contínua dos professores do ensino médio, que de uma certa forma têm a importante incumbência de motivar os futuros cientistas deste País.

Por fim, podemos dizer que a SBQ ganhou maturidade vencendo um sem número de dificuldades para preservar a idéia de uma Química de reconhecimento internacional e que tem dado significativas contribuições à Ciência Brasileira, abrindo espaços para novos desenvolvimentos na fronteira do conhecimento.

\section{AGRADECIMENTOS}

A todos aqueles que contribuíram com o seu trabalho para o engrandecimento do sonho de uma SBQ representativa e de qualidade.

\section{REFERÊNCIAS E NOTAS}

1. Filgueiras, C. A. L.; Quim. Nova 1999, 22, 147.

2. Seebach, D.; Angew. Chem., Int. Ed. 1990, 102, 1363.

3. Fioravante, C.; Pesquisa FAPESP 2000, dezembro, 3.

4. Vargas, J. I.; Quim. Nova 1997, 20 (Especial), 7.

5. Moura, A. F.; Quim. Nova 2000, 23, 851.

6. Gottlieb, O. R .; Mors, W. B.; Interciência 1978, 4, 252.

7. Balandrin, M. F.; Klocke, J. A.; Wurtele, E. S.; Bollinger, Wm. H.; Science 1985, 228, 1154.

8. Ferreira, V. F.; Barreiro, E. J.; Costa, P. R. R.; Quim. Nova 1997, $20,647$.

9. Hanessian S. Em The Total Synthesis of Natural Products: The Chiron Approach; Pergamon Press: New York, 1983.

10. Trost, B. M.; Science 1985, 227, 908.

11. Mark, S. L.; Modern Drug Discovery 2000, november, 17.

12. Barreiro, E. J.; Fraga, C. A. M. Em Química Medicinal - As Bases Moleculares da Ação dos Fármacos; Ed. Artmed: Porto Alegre, 2001, p. 53.

13. Corey, E. J.; Cheng, X.-M. Em The Logic of Chemical Synthesis; John Wiley \& Sons: New York, 1989.

14. Furlán, R. L. E.; Labadie, G. R.; Pellegrinet, S. C.; Ponzo, V. L.; Quim. Nova 1996, 19,4 .

15. Stork, G.; Niu, D.; Fujimoto, A.; Koft, E. R.; Balkovec, J. M.; Tata, J. R.; Dake, G. R.; J. Am. Chem. Soc. 2001, 123, 3239.

16. Ball, P.; Chem. Brit. 2001, october, 26.

17. Suh, E. M.; Kishi, Y.; J. Am. Chem. Soc. 1994, 116, 11205

18. Corrêa, A. G.; Quim. Nova 1995, 18, 452.

19. Danishefsky, S. J.; Masters, J. J.; Young, W. B.; Link, J. T.; Snyder, L. B.; Magee, T. V.; Jung, D. K.; Isaacs, R. C. A.; Bornmann, W. G.; Alaimo, C. A.; Coburn, C. A.; Grandi, M. J.; J. Am. Chem. Soc. 1996, 118, 2843. 
20. Nicolaou, K. C.; Guy, R. K.; Angew. Chem., Int. Ed. 1995, 34, 2079

21. Mann, J.; Chem. Brit. 2001, october, 73.

22. Holton, R. A.; Somoza, C.; Kim, H.-B.; Liang, F.; Biediger, R. J.; Boatman, P. D.; Shindo, M.; Smith, C. C.; Kim, S.; Nadizadeh, H.; Suzuki, Y. ; Tao, C.; Vu, P.; Tang, S.; Zhang, P.; Murthi, K.; Gentile, L. N.; Liu, J. H.; J. Am. Chem. Soc. 1994, 116, 1597; ibid 1994, 116, 1599; Nicolaou, K. C.; Yang, Z.; Liu, J. J.; Ueno, H.; Nantermet, P. G.; Guy, R. K.; Claiborne, C. F.; Renaud, J.; Couladouros, E. A.; Paulvannan, K.; Sorensen, E. J.; Nature 1994, 367, 630.

23. http://www.sbq.org.br/PN-NET/texto4/sintese.htm, acessada em Dezembro 2001.

24. Woodward, R. B.; Pure Appl. Chem. 1973, 33, 145.

25. Woodward, R. B.; Cava, M. P.; Ollis, W. D.; Hunger, A.; Däniker, H. U.; Schenker, K.; J. Am. Chem. Soc. 1954, 76, 4749.

26. Suh, E. M.; Kishi, Y.; J. Am. Chem. Soc. 1994, 116, 11205.

27. Para a síntese do ácido carboxílico da palitoxina ver: Armstrong, R.W.; Beau, J. M.; Cheon, S. H.; Christ, W. J.; Fujiota, H.; Ham, W.-H.; Hawkins, L. D.; Jin, H.; Kang, S. H.; Kishi, Y.; Martinelli, S. J.; McWorther, W. W.; Mizuno, M.; Nakata, M.; Stutz, A. E.; Talamas, F. X.; Taniguchi, M.; Tino, J. A.; Ueda, K.; Uenishi, J.-I.; White, J. B.; Yonaga, M.; J. Am. Chem. Soc. 1989, 111, 7525; ibid 1989, 111, 7530.

28. Negishi, E. Em Organometallic in Organic Synthesis; Wiley: New York, 1980; Pearson, J. Em Metallo-organic Chemistry; Wiley: New York, 1985; Davies, S.G. Em Organotransition Metal Chemistry: Application to Organic Synthesis; Pergamon Press: Oxford, 1982.

29. Ferreira, V. F.; Pereira, L. O. R.; de Souza, M. C. B. V.; Cunha, A.C.; Quim. Nova 2001, 24, 540.

30. Colvin, E. Em Silicon in Organic Synthesis; Buttersworths: London, 1981.

31. Larock, R. C. Em Organomercury Compounds in Organic Synthesis; Springer Verlag: New York, 1985.

32. Brown, H. C. Em Organic Synthesis via Borane; Wiley: New York, 1985.

33. Ferraz, H. M. C.; Quim. Nova 1988, 12, 155; ibid 1990, 13, 88; Ferraz, H. M. C.; Silva Jr.; L. F.; Quim. Nova 2000, 23, 216.

34. Ferraz, H. M. C.; Comasseto, J. V.; Borba, E. B.; Quim. Nova 1992, 5, 298; Comasseto, J. V.; Quim. Nova 1993, 16, 138

35. Comasseto, J. V.; Ferreira, J. T. B.; Canto, M. M.; Quim. Nova 1979, 2, 58; Liotta D. Em Organoselenium Chemistry; Wiley: New York, 1981.

36. Laszlo, P., ed.; Em Preparative Chemistry Using Supported Reagents; Academic Press: New York, 1987.

37. Kyriacon D. K. Em Electrocatalysis for Organic Synthesis; Wiley: New York, 1986.

38. Neste indicador também estão incluídos, estudos mecanísticos, cinéticos, variações e novas metodologias de análises espectroscópicas, processos aplicados, estudos fotoquímicos, parâmetros reacionais, complexação, ligantes.

39. A distinção entre I1 e I3 contem elementos de subjetividade e a atribuição dependeu do julgamento do avaliador.
40. Eliel, E. 1.; Wilen, S. H. Em Stereochemistry of Organic Compounds; John Wiley \& Sons: New York, 1994, p. 1192.

41. As sínteses ditas assimétricas, pelo conceito apresentado por Eliel, são sínteses de substâncias quirais feitas de novo a partir de substância aquiral. Quanto às sínteses ditas estereosseletivas são aquelas onde o pesquisador parte de um substrato quiral e realiza a síntese do produto desejado.

42. Marsaoli, A. J.; Valente, L.; Lukacs, G.; Resumos da Reunião Anual da SBPC, 1979.

43. Ferreira, V. F.; Quim. Nova 2001, 24, 165.

44. Sanseverino, A. M.; Quim. Nova 2000, 23, 102.

45. Dupont, J.; Quim. Nova 2000, 23, 825.

46. Sikdar, S. K.; Howell, S.G.; J. Cleaner Prod. 1998, 6, 253.

47. Sheldon, R. A.; C. R. Acad. Sci. Paris 2000, 3, 541.

48. Silva, F. M.; Jones Jr., J.; Quim. Nova, 2001, 24, 646.

\section{APÊNDICE}

\section{DIVISÃO DE QUÍMICA ORGÂNICA}

Número de filiados: 209 (atual)

2000-2002

DIRETOR:

VICE-DIRETOR:

TESOUREIRO:

Paulo Roberto R. Costa

Edson L. da S. Lima

Ronaldo A. Pilli

1998-2000

DIRETOR:

VICE-DIRETOR:

Ronaldo A. Pilli

TESOUREIRO:

Luiz Carlos Dias

Fernando Coelho

1996-1998

DIRETOR:

VICE-DIRETOR:

TESOUREIRO:

José Tercio Ferreira

Helena M. C. Ferraz

Timothy Brockson

1994-1996

DIRETOR:

VICE-DIRETOR:

José Tércio B. Ferreira

TESOUREIRO:
Maurício Gomes Constantino

Carlos Roque Duarte Correia 